\title{
BMJ Global Health Cocreated regional research agenda for evidence-informed policy and advocacy to improve adolescent sexual and reproductive health and rights in sub- Saharan Africa
}

Meggie Mwoka, ${ }^{1}$ Anthony Idowu Ajayi (D) , ${ }^{2}$ Grace Kibunja, ${ }^{1}$ Collins Cheruiyot, ${ }^{1}$ Ramatou Ouedraogo, ${ }^{2}$ Kenneth Juma, ${ }^{2}$ Emmy Kageha Igonya, ${ }^{2}$ Winnie Opondo, ${ }^{2}$ Emmanuel Otukpa, ${ }^{2}$ Caroline Kabiru, ${ }^{2}$ Boniface Ayanbekongshie Ushie ${ }^{2}$

To cite: Mwoka M, Ajayi Al, Kibunja G, et al. Cocreated regional research agenda for evidence-informed policy and advocacy to improve adolescent sexual and reproductive health and rights in sub-Saharan Africa. BMJ Global Health 2021;6:e005571. doi:10.1136/ bmjgh-2021-005571

Received 3 March 2021 Revised 13 March 2021 Accepted 15 March 2021

Check for updates

(c) Author(s) (or their employer(s)) 2021. Re-use permitted under CC BY-NC. No commercial re-use. See rights and permissions. Published by BMJ.

${ }^{1}$ Policy Engagement and Communications, African Population and Health Research Center, Nairobi, Kenya

${ }^{2}$ Population Dynamics \& Sexual and Reproductive Health and Rights, African Population and Health Research Center, Nairobi, Kenya

Correspondence to Dr Anthony Idowu Ajayi; ajayianthony@gmail.com

\section{INTRODUCTION}

The sub-Saharan Africa (SSA) region has one of the poorest adolescent sexual and reproductive health (SRH) indicators, and a multiplicity of structural and sociocultural factors contribute to these poor adolescent SRH outcomes. ${ }^{1-3}$ Prevailing sociocultural and religious beliefs characterise adolescent sexuality as a taboo. ${ }^{45}$ As a result, interventions or policies aiming to improve adolescent SRH outcomes face significant opposition. ${ }^{6}$ Additionally, vague and restrictive regulations on the right to privacy, confidentiality and informed consent to accessing SRH services limit the provision and access to SRH services to adolescents. ${ }^{7}$

Regional commitments on sexual and reproductive health and rights (SRHR), such as the ground-breaking Maputo Protocol, have explicitly recognised adolescents' right to youth-friendly SRH services, comprehensive sexuality education (CSE), safe abortion and postabortion care. ${ }^{8-10}$ Although most countries in SSA have ratified the Maputo Protocol, domestication and operationalisation remain slow. Also, where it is domesticated, poor prioritisation and resource allocation towards adolescent SRH programming, poor knowledge of the laws and policies by adolescents, services providers, communities, and societal barriers hinder effective implementation. ${ }^{11} 12$

Regional and subregional policy and advocacy actors require robust empirical evidence to facilitate domestication of the continental commitments on adolescent SRHR. In response to the expressed evidence needs, the African Population and Health Research

\section{Summary box}

One of the obstacles to domesticating and operationalising continental commitments that promote adolescent sexual and reproductive health and rights (SRHR) in sub-Saharan Africa (SSA) is the lack of stakeholder-driven research or inputs in setting the research agenda.

- This commentary describes a cocreation initiative that engaged strategic stakeholders to identify key policy goals and research priorities necessary to advance continental and subregional advocacy around adolescent SRHR in SSA.

- The development of the cocreated regional research agenda encompassed three phases: (1) a landscape analysis involving the mapping of existing research and research priorities on adolescent SRHR in SSA; (2) a 2-day cocreation workshop with regional and subregional SRHR policy, advocacy and research actors; and (3) a validation exercise where stakeholders reviewed and confirmed the research priorities.

- The emerging adolescent SRHR policy goals centered on policy and law reforms to end child marriage, implement sexuality education in and out of schools, and universal access to comprehensive and integrated sexual and reproductive health (SRH) services for adolescents.

- The main research priorities focused on understanding the needs and service access of vulnerable adolescent populations; implementation research on the delivery of comprehensive sexuality education and adolescent-friendly SRH services; understanding the impact of child marriage on health and well-being; and the analysis of legal and policy provisions addressing the age of consent to SRH services for adolescents.

- Various stakeholders, including funders and researchers, will find this research agenda useful in improving adolescent SRHR in SSA. 
Center (APHRC), under the auspices of the Challenging the Politics of Social Exclusion project, undertook a research agenda-setting process. The APHRC brought together multiple stakeholders to identify the evidence gaps hampering progress in adolescent SRH, comprehensive abortion care ${ }^{13}$ and the inclusion of sexual and gender minorities. This undertaking was in recognition that evidence is a critical lever in policy development and implementation. The cocreated research agenda seeks to bridge the gap between policy actors and researchers and facilitate mutually beneficial agendas. This commentary describes the agenda cocreation process and highlights the evidence priorities that stakeholders identified as critical to policy and advocacy processes around adolescent SRH.

\section{AGENDA CO-CREATION PROCESS}

The research agenda's cocreation involved three phases: (1) preparation, (2) cocreation and (3) validation. In the preparatory phase, we conducted a scoping review of existing adolescent SRH studies to identify critical evidence gaps. ${ }^{414}$ We also mapped key actors involved in abortion and SRH research, programming and policymaking in the region. The cocreation phase involved a 2-day research agenda-setting workshop held in October 2019 in Nairobi with the key actors identified in the preparatory phase. During the workshop, 50 representatives from 11 SSA countries identified key policy advocacy goals and priority evidence needed to advance these goals. After the workshop, participants reviewed and validated the emerging research priorities.

\section{KEY ADVOCACY GOALS OF THE NEW RESEARCH AGENDA}

At the regional level, two main advocacy goalspromoting access to education and CSE, and ending child marriage-were identified as critical in reversing the trend of poor adolescent SRH outcomes. Stakeholders identified the implementation of the Continental Education Strategy 2016-2025 as essential. They noted a need for the subcluster on Education for Health and Well-being of the African Union (AU) to develop the Continental Strategy on Education for Health and Wellbeing for Adolescents and Young People in Africa. Participants emphasised the need to further advance the AU Campaign to End Child Marriage, currently in its second phase and started in $2014 .{ }^{15}$ The campaign, which started in 2014, aims to accelerate the end of child marriage in Africa by enhancing awareness of the implications of the practice, supporting legal and policy actions, social mobilisation at the grassroots and national levels and increasing the capacity of non-state actors to undertake evidence-based policy advocacy.

In the Eastern Africa Community subregion, passing the Sexual and Reproductive Health Rights Bill was noted as a priority. The Bill includes provisions to promote adolescent and youth access to SRH services, information and commodities, regulate harmful practices such as child marriage and female genital mutilation, and ensure reintegration and access to education for pregnant and parenting girls. In the West African subregion, promoting the formulation of subregional Economic Community of West African States (ECOWAS) frameworks addressing CSE implementation for in and out-of-school adolescents was highlighted as the main policy goal.

The Southern Africa subregion, in its commitment to adolescent SRH, has already developed several policies and strategies pursuant to its commitment to adolescents SRHR. ${ }^{16}$ These focus on SRH, HIV and key populations. Implementing these policies fully, with regular monitoring and evaluation and an accountability framework, was considered the utmost priority.

\section{PRIORITY EVIDENCE NEEDS TO ADVANCE KEY POLICY ADVOCACY GOALS}

Stakeholders outlined a range of critical evidence needs to advance the above policy advocacy goals outlined above. The identified evidence requires either empirical research or synthesising and repackaging existing evidence to make it more accessible to the end-users.

\section{The scope of the problem and needs related to adolescent SRH and services}

Within this broad topic, participants underscored the need for evidence on the unique needs of specific subgroups of adolescents. Specifically, they highlighted the need for research on the SRH needs of vulnerable adolescent populations such as street children, pregnant and parenting adolescents, adolescents with disabilities, migrants and drug users. Stakeholders also identified the need for research on neglected topics such as menstrual health.

\section{The nature, extent and impact of CSE}

To advance the advocacy goal on CSE, stakeholders identified the immediate need for robust, contextualised evidence on sexuality education. Collectively, they identified the need to understand the cost of action versus inaction of CSE provision, the extent to which CSE is currently being delivered, and the impacts of CSE on SRH experiences, behaviours, and broader well-being outcomes. The evidence priorities include: (1) the nature and scope of existing demand for sexuality education among children, parents and guardians across different contexts, (2) the extent to which sexuality education is provided within family contexts, and the nature and adequacy of the skills or information conveyed to children within this context, (3) the impact of SRH information and skills on adolescents and young people's SRH and well-being including unintended pregnancy, menstrual hygiene, sexual risk behaviours and sexual and gender-based violence among different categories of adolescents, national or subnational case studies exploring the relationship between the (full) provision of CSE and sexual behaviours, SRH and broader well-being indicators among adolescents, and (4) sound interventions in the delivery of CSE in 
African contexts-documenting and evaluating CSE interventions targeting in and out-of-school adolescents.

\section{Africa's traditions and values on adolescent and young people's sexuality}

Participants underscored the importance of exploring the nature of evolving 'African' conceptions and narratives around sexuality and childhood and how such notions and narratives could reflect in the value-based elements of CSE in different contexts.

\section{Impact of child marriage on adolescents' health and well- being}

To further broaden the understanding of early child marriage's impact beyond SRH, participants noted the need for evidence on the nature and extent of the short-term, medium-term and long-term impact of early marriage on adolescents' mental health.

\section{The legal and policy architecture}

The workshop participants emphasised the need for evidence on the nature, extent and implications of discrepancies between national legislation on the age of consent to SRH services and the age at marriage, which are topical issues on the continent. They highlighted the need for research to track the extent of implementation of existing laws, policies and strategies/guidelines, at regional, subregional and country levels.

\section{CROSS-CUTTING APPROACHES FOR BETTER UPTAKE OF EVIDENCE}

The stakeholders identified a set of approaches and principles to inform and guide research geared towards adolescent SRH policies and advocacy. First, they underscored the need for researchers to explore and use contextsensitive terminologies (eg, CSE vs life skills education, abortion vs pregnancy termination). Second, they pointed out that research ought to produce 'data' and evidence that brings to the fore-including through visual products-the lived experiences, human stories, and faces of individuals or groups. Accordingly, stakeholders identified participatory research - coproduction with communities or groups of interest - as essential in knowledge production. Third, they underscored the need for researchers to adopt an intersectionality approach (considering, eg, key populations, disability, socioeconomic status, gender, geographical location, etc) to identify marginalised groups of adolescents. Finally, active and effective strategies to engage intended users of generated findings were considered integral to all research. Participants highlighted the need for deliberate approaches to appraise and build media capacity to frame and report evidence tailored to targeted audiences meaningfully. They advocated for problem-driven political economy analyses to understand decision-makers' motivation, interests and values, identify who holds power, who to engage and how to move the agenda forward. These analyses were noted to ensure the framing of information in ways that would change the 'hearts and minds' of those central to the decision-making.

Beyond these approaches, participants emphasised the need for research to move beyond 'data-rich countries and regions. They noted a clear need to pursue the generation of evidence in Francophone and Lusophone countries in Central, Eastern and Western Africa. Participants noted that the evidence generated should enable comparative analysis and opportunities for cross-country peer exchange and learning within the context of subregional or regional bodies. Finally, the politics of research funding need to be understood and addressed to ensure adequate financial resources to undertake the research agenda.

\section{Ways forward}

Sustained engagement and collaboration between policymakers, researchers and civil society are expected to push forward the translation of evidence to action, making our research agenda more timely, relevant and to ultimately improve the health and well-being of adolescents and young people in SSA.

\section{Twitter Anthony Idowu Ajayi @aiajayi}

Acknowledgements The authors would like to extend thanks to all stakeholders and organisations that participated in the cocreated research agenda meeting.

Contributors MM, AIA, GK, CC, KJ, EKI, RO, WO, EO, CK and BAU conceived of the presented paper. MM led the writing of the manuscript with significant support from AIA, CK and BAU. All authors reviewed the results, provided feedback and approved the final version.

Funding The cocreation meeting was supported by a grant from the African Regional Office of the Swedish International Development Cooperation Agency, Sida Contribution No. 12103 for APHRC's Challenging the Politics of Social Exclusion project.

Competing interests None declared.

Patient consent for publication Not required.

Provenance and peer review Not commissioned; internally peer reviewed.

Data availability statement There are no data in this work.

Open access This is an open access article distributed in accordance with the Creative Commons Attribution Non Commercial (CC BY-NC 4.0) license, which permits others to distribute, remix, adapt, build upon this work non-commercially, and license their derivative works on different terms, provided the original work is properly cited, appropriate credit is given, any changes made indicated, and the use is non-commercial. See: http://creativecommons.org/licenses/by-nc/4.0/.

\section{ORCID iD}

Anthony Idowu Ajayi http://orcid.org/0000-0002-6004-3972

\section{REFERENCES}

1 Chandra-Mouli V, Svanemyr J, Amin A, et al. Twenty years after International Conference on population and development: where are we with adolescent sexual and reproductive health and rights? $J$ Adolesc Health 2015;56:S1-6.

2 Melesse DY, Mutua MK, Choudhury A, et al. Adolescent sexual and reproductive health in sub-Saharan Africa: who is left behind? BMJ Glob Health 2020;5:e002231.

3 Ajayi Al, Somefun OD. Transactional sex among Nigerian university students: the role of family structure and family support. PLoS One 2019;14:e0210349.

4 Ajayi Al, Ushie BA, Mwoka M, et al. Mapping adolescent sexual and reproductive health research in sub-Saharan Africa: protocol for a scoping review. BMJ Open 2020;10:e035335. 
5 Challa S, Manu A, Morhe E, et al. Multiple levels of social influence on adolescent sexual and reproductive health decision-making and behaviors in Ghana. Women Health 2018;58:434-50.

6 Chandra-Mouli V, Lane C, Wong S. What does not work in adolescent sexual and reproductive health: a review of evidence on interventions commonly accepted as best practices. Global Health: Science and Practice 2015;3:333-40.

7 World Health Organization. Health for the world's adolescents: a second chance in the second decade: summary. Geneva: World Health Organization, 2014.

8 Africa Union Commission. Protocol to the African Charter on Human and People's Rights on the Rights of Women in Africa. In: protocol $M$, ed. Maputo: African Union, 2003.

9 Africa Union. Maputo plan of action for implementing the continental policy framework on sexual and reproductive health and rights. Addis Ababa - Ethiopia: International Planned Parenthood Liaison Office to the African Union and ECA, 2014.

10 Africa Union Commission. Addis Ababa Declaration on population and development in Africa beyond 2014. In: development $A R C o P a$, ed. Addis Ababa, Ethiopia: Africa Union Commission, 2013.
11 Africa Union. State of African population report 2017. Keeping rights of girls, adolescents and young women at the centre of Africa's demographic dividend. Addis Ababa, Ethiopia: Africa Union, 2017.

12 African Union. Au roadmap on harnessing the demographic dividend through investments in youth. Addis Ababa, Ethiopia: African Union, 2017.

13 Ajayi Al, Ouedraogo R, Juma K, et al. Research priorities to support evidence-informed policies and advocacy for access to safe abortion care in sub-Saharan Africa. Sex Reprod Health Matters 2021;29:1881207.

14 Ajayi Al, Otukpa EO, Mwoka M, et al. Adolescent sexual and reproductive health research in sub-Saharan Africa: a scoping review of substantive focus, research volume, geographic distribution and Africa-led inquiry. BMJ Glob Health 2021;6:e004129.

15 Union A. African common position on the African Union campaign to end child marriage in Africa. Addis Ababa, Ethiopia: African Union, 2014.

16 The Civil Society Organisations supporting the SADC SRHR Strategy. The sexual and reproductive health and rights strategy for the SADC region (2019 - 2030). South Africa: SRHR Africa trust (SAT. South Africa: SRHR Africa Trust (SAT), 2018. 